\section{The peak shift and behavioral contrast: Effects of discrimination training with delayed reinforcement*}

\author{
DONALD M. WILKIE \\ University of British Columbia, Vancouver 8, B.C., Canada
}

Five pigeons were initially reinforced according to a variable-interval 1 -min schedule for pecking during two successively alternating stimuli (line tilts of 0 and $+45 \mathrm{deg}$ ). When the reinforcement associated with the $+45-\mathrm{deg}$ line was later delayed by $2 \mathrm{sec}$, the rate of responding during that stimulus decreased. The rate of responding during the 0 -deg line increased (behavioral contrast). Subsequent generalization testing on the line-tilt continuum revealed a peak or area shift away from the +45-deg line.

In the present experiment, pigeons were exposed to a situation in which different delays of reinforcement were associated with different successively presented stimuli. In previous experiments (Keller, 1970; Wilkie, 1970,1971 ), it has been found that behavioral contrast (Reynolds, 1961) occurs in such a situation. The purpose of the present experiment was, first, to attempt a systematic replication of this behavioral contrast effect and, second, to determine if a generalization-gradient peak shift (Hanson, 1959) would occur after the establishment of a successive discrimination based on differential delay of reinforcement. METHOD

The Ss were five adult White King pigeons. Three of the pigeons (A, B, and $C$ ) were experimentally naive; the other two pigeons ( $D$ and $E$ ) had previously served in a discrimination experiment. Throughout the experiment, the birds were maintained at $80 \%$ of their free-feeding body weights by grain obtained during experimental sessions. Water and grit were always available in the home cage.

The experimental space was a three-key operant chamber for pigeons (BRS-Foringer Model PS-004). In the present experiment, only the center key was used. Operation of this key required a force of about $0.196 \mathrm{~N}$. Directly behind this transparent key was an Industrial Electronics Engineers' one-plane readout cell which displayed a $2.54 \times 0.32 \mathrm{~cm}$ white line at different orientations on a red background. Directly below the key was a grain feeder. During the reinforcement period, which consisted

*This research was supported by Grant 26-9947 from the University of British Columbia Committee on Research. I wish to thank $R$. Wong for lending some of the equipment and D. Ramer for assistance in running the Ss. of $5.0 \mathrm{sec}$ of access to mixed grain, stimuli on the display cell were extinguished and a small lamp illuminated the grain in the feeder tray. The display cell and feeder lamp were the only sources of illumination in the chamber. Extraneous sounds were partially masked by white noise and the chamber air blower. Automatic scheduling of stimulus presentations, reinforcement, etc., was accomplished by solid-state digital logic. Data were recorded on digital counters.

\section{Baseline Training}

Following a short period of preliminary training, the Ss were exposed to line orientations of either 0 (vertical) or +45 deg (right of vertical) on a red background. These stimuli were presented successively and alternated with each other every $3.0 \mathrm{~min}$. During both line tilts, keypecking was immediately reinforced according to a variable-interval 1.0-min schedule consisting of a rectangular distribution of interreinforcement intervals ranging from 5 to $125 \mathrm{sec}$. For four of the pigeons $(\mathrm{A}, \mathrm{B}, \mathrm{D}$, and $\mathrm{E})$, a $5.0-\mathrm{sec}$ period of blackout (display cell off) followed each alternation. These conditions remained in effect for a minimu $m$ of 14 sessions.

\section{Discrimination Training}

During this stage of the experiment, keypecks following a reinforcement assignment during the +45-deg line began a 2.0 -sec delay interval, at the end of which the reinforcer was delivered, provided no additional pecks had occurred. Each peck during the delay interval postponed reinforcement by $2.0 \mathrm{sec}$. For Birds A, $\mathrm{B}$, and $\mathrm{C}$, a stimulus was correlated with the delay interval; for Brids A and $B$, the red background changed to black; for Bird C, the red background changed to black and the $+45 \cdot \operatorname{deg}$ line was turned off. No stimulus was associated with the delay interval for the other two Ss. Reinforcement during the 0-deg line continued to be delivered without an intervening delay period. These conditions remained in effect for at least nine sessions. During this, as well as the preceding, stage of the experiment, sessions were $1.0 \mathrm{~h}$ in duration and were scheduled 7 days per week. In all sessions during both stages, reinforcements not obtained at the completion of a stimulus presentation were cancelled. Generalization Test

Following the discrimination training with differential reinforcement delay, the birds were given a conventional generalization test on the line-tilt continuum. During the test, conducted in extinction, different line tilts $( \pm 90, \pm 67.5, \pm 45$, \pm 22.5 , and 0 deg for Birds $A, B$, and C; $\pm 67.5, \pm 45, \pm 22.5$, and $0 \mathrm{deg}$ for Birds $D$ and $E$ ) on a red background were presented. Each stimulus was presented six times in a sequence which was blocked so that each stimulus was presented before another was repeated. Stimulus presentations were of $1.0-\mathrm{min}$ duration and were separated for all birds except $\mathrm{C}$ by 5.0-sec blackouts.

RESULTS AND DISCUSSION

The introduction of the differential delay of reinforcement procedure produced behavioral contrast. The response rate during the 0 -deg line increased over the rate prevailing during the baseline sessions. The delay procedure reduced the rate of responding in the presence of the \pm 45 -deg line. This contrast effect was shown by each of the Ss. These response rate changes are shown, in summary form, in Table 1 . The table shows the average response rate during both the 0 - and $\pm 45-$ deg line tilts during the differential delay of reinforcement sessions divided by the average response rates of the baseline sessions.

The finding that correlating different delays of reinforcement with different successively presented stimuli produces behavioral contrast replicates previous experiments (Keller, 1970; Wilkie, 1970,1971 ). Not replicated in the present experiment, however, was

Table 1

Ratio of Average Response Rate During Differential Delay Condition to Average Response Rate During Baseline*

Relative Response Rates

\begin{tabular}{cccccc}
\cline { 2 - 6 } Stimulus & S A & S B & S C & S D & S E \\
\hline 0 Deg & 1.08 & 1.55 & $\mathbf{1 . 5 7}$ & $\mathbf{1 . 2 1}$ & $\mathbf{1 . 2 9}$ \\
+45 Deg & 0.68 & $\mathbf{0 . 7 8}$ & $\mathbf{0 . 7 2}$ & $\mathbf{0 . 3 9}$ & $\mathbf{0 . 3 2}$
\end{tabular}

* Ratios are based on last five sessions under each condition. Ratios larger than 1.00 indicate an increased rate of responding during the delay condition. 


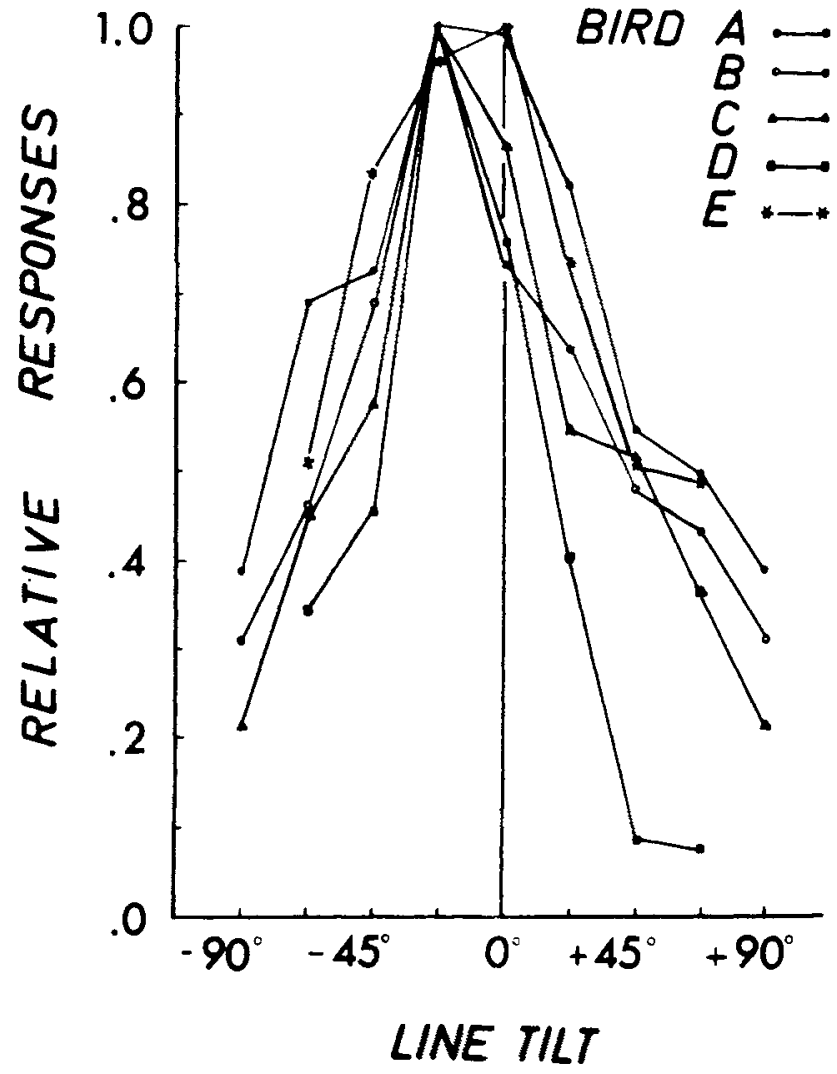

Fig. 1. Relative generalization gradients obtained after discrimination training in which a line tilt of $\mathbf{0}$ deg was associated with immediate reinforcement and a line tilt of $+45 \mathrm{deg}$ was associated with a 2 -sec delay of reinforcement.

Wilkie's (1971) finding that a short delay of reinforcement produced little, if any, consistent decrease in response rate during the stimulus correlated with the reinforcement delay. All Ss in the present experiment showed a decreased rate of responding during the stimulus associated with the delay of reinforcement.

The results of the generalization test are shown in Fig. 1. All of the birds except $E$ showed a peak shift, peaking at $-22.5 \mathrm{deg}$ rather than at 0 deg. All of the birds, including $E$, showed an "area shift" (Terrace, 1966). Each bird made more responses during the generalization test to line tilts to the left (negative) than to the right (positive) of the 0 deg line. These data are summarized in Table 2.
Table 2

Percent of Responses Made During Generalization Test to Line Tilts to the Right (Positive) and Left (Negative) of Vertical

\begin{tabular}{llc} 
& \multicolumn{2}{c}{ Percent of Responses } \\
\cline { 2 - 3 } S & Left & Right \\
\hline A & 60.8 & 39.2 \\
B & 57.3 & 42.7 \\
C & 58.0 & 42.0 \\
D & 76.6 & 23.4 \\
E & 57.0 & 43.0 \\
\hline
\end{tabular}

preference hypotheses of contrast and the peak shift. Since the number of reinforcements associated with the two line tilts in the present experiment was approximately equal (see Table 3 ), the hypothesis that contrast and the peak shift are due to a reduced frequency of reinforcement is not supported. (The data for Birds D and $\mathrm{E}$ are perhaps the most relevant here, since it can be aruged that the other Ss received only conditioned reinforcement during the $+45-\mathrm{deg}$ stimulus.)

\section{REFERENCES}

BLOOMFIELD, T. M. Behaviourai contrast and the peak shift. In R. M. Gilbert and N. S. Sutherland (Eds.), Animal discrimination learning. New Yodk: Academic Press, 1969. Pp. 215-241.

CHUNG, $S$ H \& HERRNSTEIN, $R$. Choice and delay of reinforcement. Joumal of the Experimental Analysis of Behavior, 1967, 10,67-74.

HANSON, H. M. Effects of discrimination training on stimulus generalization. Journal of Experimental Psychology, $1959,4,321-334$.

KELLER, J. V. Behavioral contrast under multiple delays of reinforcement. Psychonomic Science, 1970, 20, 257-258.

REYNOLDS, G. S. Behavioral contrast. Journal of the Experimental Analysis of Behavior, 1961, 4, 57-71.

TERRACE, $H$. S. Stimulus control. In W. $K$. Honig (Ed.), Operant behavior: Areas of research and application. New York: Appleton-Century-Crofts, 1966. Pp. 271-344.

WILKIE D M On some determinants of behavioral contrast. Unpublished doctoral dissertation, University of Manitoba, 1970.

WLKIE, D. M. Delayed reinforcement in a multiple schedule. Journal of the Experimental Analysis of Behavior, 1971 , $16,233-239$.

Table 3

The Average Number of Obtained Reinforcements*

\begin{tabular}{|c|c|c|c|c|c|c|c|c|c|c|}
\hline & \multicolumn{10}{|c|}{ Average Number of } \\
\hline & \multicolumn{2}{|c|}{$S A$} & \multicolumn{2}{|c|}{ S B } & \multicolumn{2}{|c|}{ S C } & \multicolumn{2}{|c|}{ S D } & \multicolumn{2}{|c|}{$S E$} \\
\hline & 0 Deg & +45 Deg & $0 \mathrm{Deg}$ & +45 Deg & $0 \mathrm{Deg}$ & +45 Deg & 0 Deg & +45 Deg & $0 \mathrm{Deg}$ & +45 Deg \\
\hline $\begin{array}{l}\text { Baseline } \\
\text { Differential Delay }\end{array}$ & $\begin{array}{l}28.0 \\
27.8\end{array}$ & $\begin{array}{l}27.0 \\
27.2\end{array}$ & $\begin{array}{l}27.4 \\
26.8\end{array}$ & $\begin{array}{l}26.4 \\
26.4\end{array}$ & $\begin{array}{l}26.6 \\
27.0\end{array}$ & $\begin{array}{l}27.2 \\
26.6\end{array}$ & $\begin{array}{l}29.6 \\
29.8\end{array}$ & $\begin{array}{l}28.6 \\
28.6\end{array}$ & $\begin{array}{l}28.6 \\
27.8\end{array}$ & $\begin{array}{l}28.6 \\
28.2\end{array}$ \\
\hline
\end{tabular}

*Averages are based on last five sessions of baseline and last five sessions of differential delay of reinforcement 